\title{
Serum Citrulline Levels Exhibit Circadian Variation and Fluctuations in Relation to Food Intake in Mice
}

\author{
Christine J. Park ${ }^{a}$, Matthew P. Shaughnessy ${ }^{a}$, Sarah J. Armenia ${ }^{a}$, Robert A. Cowles ${ }^{a}$, b
}

\begin{abstract}
Background: Plasma citrulline is a nonessential amino acid synthesized almost exclusively by enterocytes of the small intestine. Correlation between post-operative plasma citrulline levels and remnant small bowel mass and function has led to its use as a simple biomarker of functional intestinal mass in adults and children, with a proposed prognostic value for achieving enteral autonomy in the setting of intestinal failure. While it is standard to measure fasting levels in humans, the optimal timing of blood draws in relation to food intake and time of day has not been standardized and is poorly studied in animal models. We hypothesize that serum citrulline levels vary both throughout the day and with relation to food intake in mice.
\end{abstract}

Methods: Serum citrulline levels were measured from 12 C57BL/6 mice (6 - 9 weeks old) in the mornings and evenings, either after $\mathrm{ad}$ libitum food intake or after $8-12 \mathrm{~h}$ of access to water only. Blood draws for each experimental set-up were performed 1 week apart according to our Institutional Animal Care and Use Committee (IACUC) guidelines for acceptable blood collection volumes for survival procedures. At the end of the experiment, mice were euthanized and small intestine was harvested for morphometric measurements. Group means were compared using Student's $t$-test with significance assumed for $\mathrm{P}<0.05$.

Results: After withholding chow for 8 - 12 h, serum citrulline levels were significantly greater in the morning compared to levels drawn in the evening. When mice were allowed ad libitum chow, there was no significant difference in serum citrulline levels drawn in the morning compared to the evening. There was no difference detected in villus height across the different experimental conditions.

Conclusions: Serum citrulline levels exhibit circadian variation and fluctuations in relation to food intake in mice, without apparent concurrent changes in enterocyte mass. There was no diurnal variation of serum citrulline levels in fed mice whereas fasted mice had significantly higher levels of serum citrulline in the morning compared to

Manuscript submitted January 17, 2019, accepted February 15, 2019

aDepartment of Surgery, Section of Pediatric Surgery, Yale School of Medicine, 333 Cedar Street, FMB 131, New Haven, CT 06510, USA

${ }^{b}$ Corresponding Author: Robert A. Cowles, Department of Surgery, Section of Pediatric Surgery, Yale School of Medicine, 333 Cedar Street, FMB 131, New Haven, CT 06510, USA. Email: robert.cowles@yale.edu

doi: https://doi.org/10.14740/gr1146 the evening. These findings underscore the paramount importance of consistent sample collection strategies in the setting of translational research.

Keywords: Citrulline; Circadian variation; Small intestine; Murine; Research

\section{Introduction}

Citrulline is a nonessential amino acid synthesized almost exclusively by enterocytes of the small intestine [1]. While citrulline is not typically incorporated into functional protein products, citrullination, a process of post-translational deimination of protein-embedded arginine residues, has gained recent interest in the biomedical research community due to its effects on transcription and cell proliferation with significant implications in cancer biology $[2,3]$. Other recent studies have discovered citrullination as a mechanism employed by certain bacterial pathogens to evade the human innate immune defenses, potentially identifying targets for novel antimicrobial therapy [4]. Dysregulation of citrullination is also found to be a major factor in the pathogenesis of rheumatic diseases and autoantibodies against citrulline-containing peptides have become a key element in the diagnosis of rheumatoid arthritis $[5,6]$. On the other hand, circulating citrulline produced by enterocytes plays a critical role in a number of metabolic pathways, notably as the precursor to arginine, and as a key player in the urea and nitric oxide cycles [7].

Clinically, plasma citrulline has been postulated to be a biomarker for functional enterocyte quantity, or mass, given that circulating levels depend only on de novo enterocyte production [8]. Thus, it is theorized that a greater number of enterocytes result in higher serum citrulline content. Additionally, plasma levels are independent of an individual's nutritional status or the presence of local or systemic inflammation [9]. Therefore, while intestinal failure is a clinical diagnosis indicating the need for supplemental parenteral nutrition for survival and growth, findings of a positive correlation between post-operative plasma citrulline levels and remnant small bowel mass have led to its use as a simple biomarker of functional intestinal epithelial mass in adults and children with intestinal failure [8, 10-13], with a proposed prognostic value for achieving enteral autonomy [14]. Furthermore, it is a useful tool for monitoring the extent of villous atrophy and intestinal mucosal toxicity in villous atrophy diseases and acute mucosal enter- 
opathy from antineoplastic therapies, respectively [8, 15-17]. In congruence with standard collection methods employed for other biochemical assays, studies in humans have demonstrated that the optimal timing for citrulline measurements is during the post-absorptive fasting state, likely related to citrulline's enterocyte origin [18]. However, the ideal timing of blood draws in relation to food intake and time of day is poorly defined in animal models. Thus, we designed a controlled study aimed at defining the ideal conditions for citrulline blood draws in mice with the hypothesis that serum citrulline levels vary with time of day and with relation to food intake.

\section{Materials and Methods}

\section{Animals}

C57BL/6 wild-type (WT) mice (Jackson Lab, Farmington, CT, USA) were housed under pathogen-free conditions on a 12-h dark/light cycle with access to food and water ad libitum. Ageand weight-matched mice of both genders (age 6 - 9 weeks) were used for experiments. Animal protocols were approved by Yale University's Institutional Animal Care and Use Committee (IACUC).

\section{Serum citrulline collection and analysis}

Blood samples to assess serum citrulline levels were drawn from 12 mice at various time points: either in the mornings ( $8-10 \mathrm{am})$ or evenings ( $5-7 \mathrm{pm})$, and either after ad libitum food intake or after $8-12 \mathrm{~h}$ of access to water only. Blood draws for each experimental set-up were performed 1 week apart according to IACUC guidelines for acceptable blood collection volumes for survival procedures. Mice were not segregated into specific cohorts, but rather randomly assigned to different blood collection procedures depending on the week. Approximately $100 \mu \mathrm{L}$ of blood was obtained from each animal via a standard retrobulbar technique and collected into standard Eppendorf tubes. Serum then was isolated and stored in $-80^{\circ} \mathrm{C}$ until further analysis. Citrulline levels were quantified in duplicates with a citrulline assay kit (Cell Biolabs, San Diego, CA, USA) and samples were analyzed in triplicates spectrophotometrically by measuring absorption at $560 \mathrm{~nm}$ against standard citrulline curves. It is important to note that while much of the published literature on citrulline report plasma levels, there is no significant difference in results or interpretation between serum and plasma citrulline [8].

\section{Bowel harvest}

To compare morning and evening anatomical parameters between fasted and fed animals, mice (am/fasted $n=4 ; \mathrm{pm} /$ fasted $n=4$; am/fed $n=2 ; p m / f e d ~ n=2)$ were euthanized by $\mathrm{CO}_{2}$ asphyxiation. The small intestine was identified from the ligament of Treitz to ileocecal valve and harvested by sharp dissection. The bowel was flushed with $10 \%$ neutral buffered formalin (NBF) and 2-cm segments of proximal, middle and distal small bowel were isolated and fixed in $10 \%$ NBF for at least $12 \mathrm{~h}$ before paraffin embedding and mounting on slides.

\section{Anatomical measurement of mucosal parameters}

Paraffin sections underwent standard hematoxylin and eosin staining. The slides were examined at $200-400 \times$ using standard brightfield microscopy (Axio Imager M1, Zeiss, Oberkochen, Germany) and analyzed using ImageJ software (NIH, Bethesda, MD, USA). Villi were measured only when intact from crypt-villus junction to crypt-villus junction with a visible central lacteal. At least 30 villi were measured per animal spanning the proximal, middle and distal small intestine.

\section{Statistical analysis}

Statistical analysis was performed using GraphPad Prism version 7.0a for Mac OS X (GraphPad Software, La Jolla, CA, USA). Group means were compared using Student's $t$-test with significance assumed for $\mathrm{P}<0.05$.

\section{Results}

\section{Serum citrulline}

When mice were fed freely, there was no significant difference between serum citrulline levels with time of day (am $599.9 \pm$ $17 \mu \mathrm{m}$ vs. pm $654 \pm 28.5 \mu \mathrm{m}, \mathrm{P}=0.12$; Fig. 1a). However, when chow was held for $8-12 \mathrm{~h}$, serum citrulline levels were significantly higher when drawn in the morning compared to evenings (am $767.1 \pm 72 \mu \mathrm{m}$ vs. pm $501 \pm 71.1 \mu \mathrm{m}, \mathrm{P}=0.01$; Fig. 1b). With the same dataset, comparison of serum citrulline levels in regards to food intake did not differ significantly with time of day (am fasted 767.1 $\pm 72 \mu \mathrm{m}$ vs. fed $599.9 \pm 17 \mu \mathrm{m}$, $\mathrm{P}=0.08 ; \mathrm{pm}$ fasted $501 \pm 71.1 \mu \mathrm{m}$ vs. fed $654 \pm 28.5 \mu \mathrm{m}, \mathrm{P}$ $=0.12$ ).

\section{Villus height}

Changes in enterocyte mass, or quantity, are commonly associated with changes in villus height (VH). Thus, as an estimate of enterocyte mass between mice, VH was measured spanning the entire small intestine. There was no significant difference in $\mathrm{VH}$ between all four experimental groups (Fig. 2a-e). The mean \pm SEM VHs were as follows: am fasted $\mathrm{VH}=263.6 \pm$ $8.123 \mu \mathrm{m} ; \mathrm{pm}$ fasted $\mathrm{VH}=260.3 \pm 7.665$; am fed $\mathrm{VH}=258.4$ \pm 11.52 ; pm fed $\mathrm{VH}=284.6 \pm 14.21(\mathrm{P}>0.05$ for all comparisons).

\section{Discussion}

In this study, we demonstrate that serum citrulline levels exhibit diurnal variation, particularly during the fasting state in 


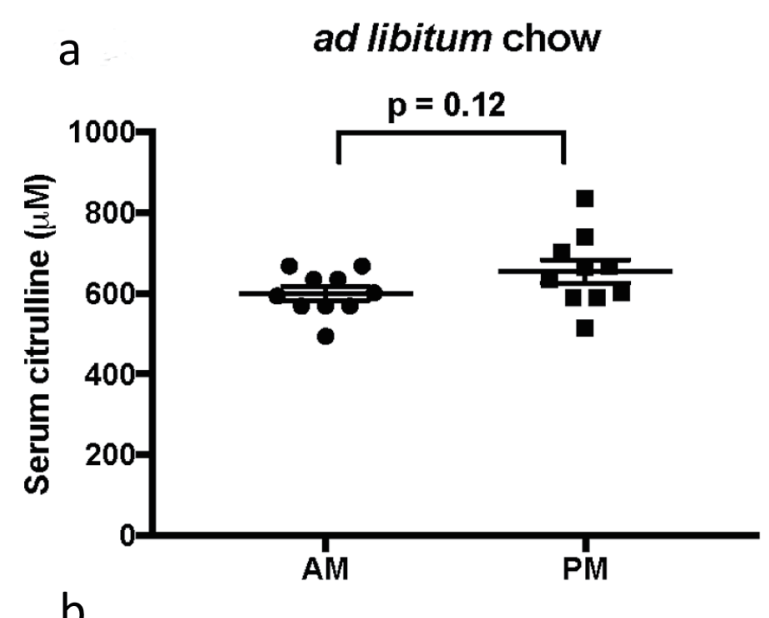

b

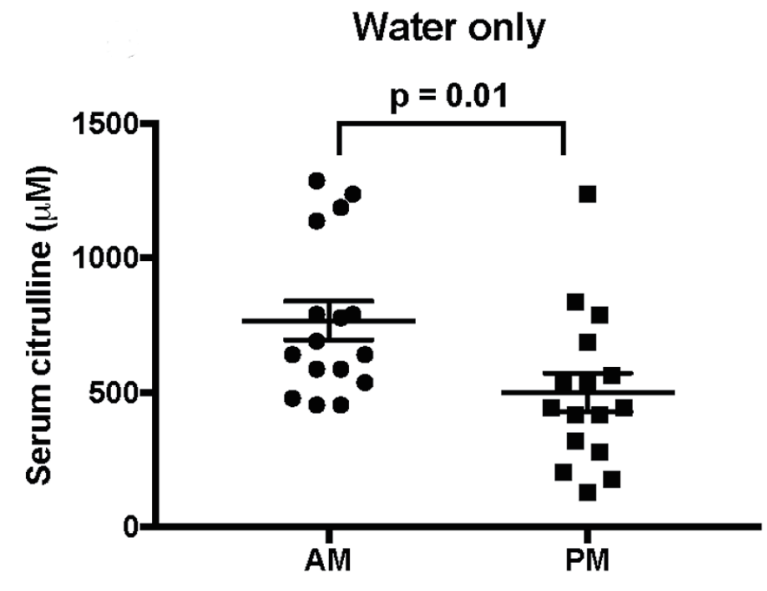

Figure 1. Comparison of mean \pm SEM serum citrulline in the morning and evening, (a) with or (b) without food.

mice, without apparent concurrent changes in enterocyte mass. Specifically, serum citrulline levels were higher in the mornings compared to evenings in mice which were only exposed to drinking water for $8-12 \mathrm{~h}$, while there was no diurnal variation of serum citrulline levels in mice fed freely. Conversely, when blood draws were performed at a consistent time of day, food status did not appear to affect serum citrulline levels. In addition, while we would expect citrulline levels to correlate with enterocyte mass, $\mathrm{VH}$, our surrogate measure of enterocyte mass, did not fluctuate along with citrulline levels and did not demonstrate any significant differences between time of day and with relation to food intake.

Although its metabolism has not yet been completely elucidated, citrulline in the body is carefully regulated. In simple terms, enterocytes synthesize and release citrulline from its precursor glutamine, which is then taken up by the kidneys and converted into arginine [19]. Some have proposed that this interorgan pathway of circulating citrulline serves as a mechanism to protect arginine from excessive degradation by the liver, which is corroborated by observed increases in enzymatic activity of this pathway during fasting states or when protein intake is low [7]. Furthermore, these findings are confirmed in humans and adult omnivorous mammals such as pigs, but not in strictly carnivorous or herbivorous animals such as cats and sheep $[20,21]$. This suggests that the citrulline pathway may serve as an alternative to the arginine pathway and therefore, allow for rapid responses to changes in dietary protein intake according to available nitrogen supply [22]. Accordingly, in human studies, citrulline levels have been found to be reduced by approximately $10-20 \%$ in the post-prandial period, when "wasting" of arginine is permissible [7, 8]. These findings are consistent with our study results, where we demonstrate increase in serum citrulline levels in the mornings after a period of fasting. During this state, we postulate that the murine body is in "protein preservation mode", where the citrulline pathway is the principal route for glutamine metabolism. In contrast, in the evenings, or during the dark cycle, which is when mice have preference for food intake [23], serum citrulline levels may have dropped in anticipation of protein intake in this group of mice which were only fasted for an isolated period of time. In mice which are acclimated to daytime fasting, it may be reasonable to expect this effect to diminish and would require future studies for verification.

Gross elevation and reduction of citrulline levels can be further affected by several factors. Increase in citrulline concentration may be due to increased production or decreased utilization. The former occurs with increased intestinal production in response to a low protein diet as discussed above, while the latter corresponds to decrease in clearance by the kidneys, such as in kidney failure. By the same note, decrease in citrulline concentration would be observed with a significant reduction in functional enterocyte mass and therefore, diminished production, as seen in intestinal failure or acute mucosal enteropathy. However, decreased citrulline concentration due to increased utilization has not been described in humans or animal models [8].

In our study, we demonstrate diurnal variation in citrulline levels apparently unrelated to $\mathrm{VH}$ which was used as a surrogate measure of enterocyte mass. The more likely explanation for our findings would be fluctuations in citrulline metabolism at the subcellular level rather than variations in structural changes in the intestinal mucosa. Diurnal variation is observed in numerous aspects of small intestine physiology including transporter and enzyme activities, mitotic activity of crypt cells, lymphocyte subpopulations and gut microbiome population, to name a few [24-28]. Therefore, it is possible that citrulline levels are subject to similar patterns of dynamic and cyclical gene expression that is responsive to food intake and to the host's central circadian clock.

In light of these findings, we propose employing consistent and standardized sample collection methods when considering the use of citrulline levels as a biomarker for functional enterocyte mass in the laboratory setting, similar to how these levels are obtained clinically. Specifically, samples should be collected in the post-absorptive, fasting state and at the same time of day across experiments for meaningful comparison.

This study has important limitations. While experimental conditions are controlled for groups for which food was withheld, groups fed freely are subject to disparities in timing and amount of food intake relative to sample collection. Mice are nocturnal animals and have been observed to exhibit a cyclical feeding pattern, with highest food intake during their nighttime active phase [23]. Therefore, our findings in the fed group may 

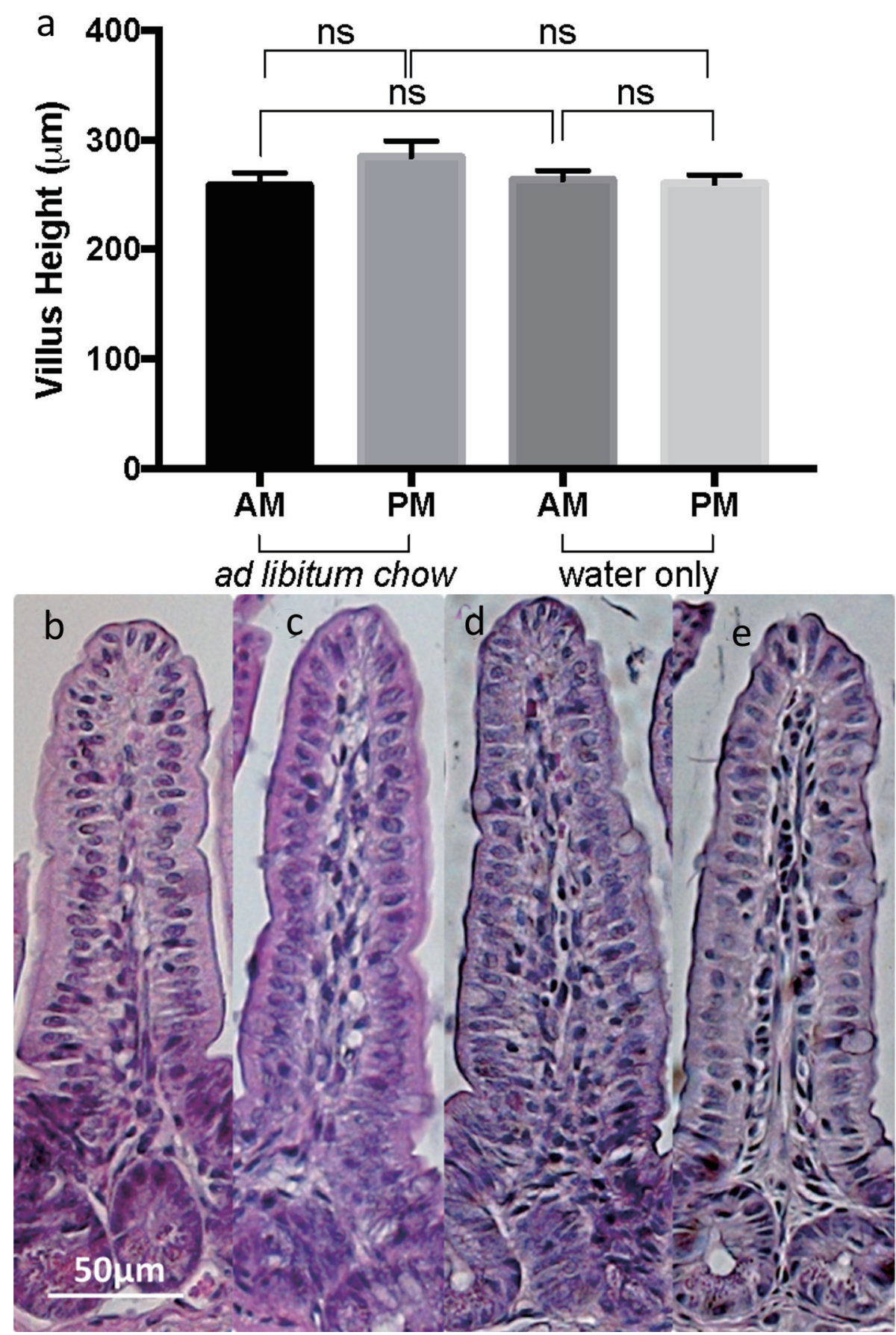

Figure 2. (a) Comparison of mean \pm SEM villus height in the morning and evening, with or without food. Representative histologic sections taken at 200× magnification for mice (b) fed freely, morning harvest, (c) fed freely, evening harvest, (d) fasted, morning harvest, and (e) fasted, evening harvest.

not strictly represent post-prandial conditions.

\section{Conclusions}

This is a preliminary study performed with the objective to identify the most suitable timing and method for diagnostic measurements of serum citrulline levels in laboratory mice. We demonstrate that serum citrulline levels are significantly higher in the mornings compared to the evenings in fasted mice, while this variation was not found in mice fed freely. Given our findings, we recommend collecting post-absorptive citrulline samples from fasted mice at a consistent time of day across experiments. 


\section{References}

1. Windmueller HG, Spaeth AE. Source and fate of circulating citrulline. Am J Physiol. 1981;241(6):E473-480.

2. Sharma P, Lioutas A, Fernandez-Fuentes N, Quilez J, Carbonell-Caballero J, Wright RHG, Di Vona C, et al. Arginine citrullination at the C-terminal domain controls RNA Polymerase II transcription. Mol Cell. 2019;73(1):84-96 e87.

3. Yuzhalin AE, Gordon-Weeks AN, Tognoli ML, Jones K, Markelc B, Konietzny R, Fischer R, et al. Colorectal cancer liver metastatic growth depends on PAD4-driven citrullination of the extracellular matrix. Nat Commun. 2018;9(1):4783.

4. Stobernack T, du Teil Espina M, Mulder LM, Palma Medina LM, Piebenga DR, Gabarrini G, Zhao X, et al. A secreted bacterial peptidylarginine deiminase can neutralize human innate immune defenses. MBio. 2018;9(5).

5. Schellekens GA, de Jong BA, van den Hoogen FH, van de Putte LB, van Venrooij WJ. Citrulline is an essential constituent of antigenic determinants recognized by rheumatoid arthritis-specific autoantibodies. 1998. J Immunol. 2015;195(1):8-16.

6. Whiting PF, Smidt N, Sterne JA, Harbord R, Burton A, Burke M, Beynon R, et al. Systematic review: accuracy of anti-citrullinated Peptide antibodies for diagnosing rheumatoid arthritis. Ann Intern Med. 2010;152(7):456464; W155-466.

7. Rabier D, Kamoun P. Metabolism of citrulline in man. Amino Acids. 1995;9(4):299-316.

8. Crenn P, Messing B, Cynober L. Citrulline as a biomarker of intestinal failure due to enterocyte mass reduction. Clin Nutr. 2008;27(3):328-339.

9. Papadia C, Sherwood RA, Kalantzis C, Wallis K, Volta U, Fiorini E, Forbes A. Plasma citrulline concentration: a reliable marker of small bowel absorptive capacity independent of intestinal inflammation. Am J Gastroenterol. 2007;102(7):1474-1482.

10. Jianfeng G, Weiming Z, Ning L, Fangnan L, Li T, Nan L, Jieshou L. Serum citrulline is a simple quantitative marker for small intestinal enterocytes mass and absorption function in short bowel patients. J Surg Res. 2005;127(2):177182.

11. Luo M, Fernandez-Estivariz C, Manatunga AK, Bazargan N, Gu LH, Jones DP, Klapproth JM, et al. Are plasma citrulline and glutamine biomarkers of intestinal absorptive function in patients with short bowel syndrome? JPEN J Parenter Enteral Nutr. 2007;31(1):1-7.

12. Rhoads JM, Plunkett E, Galanko J, Lichtman S, Taylor L, Maynor A, Weiner T, et al. Serum citrulline levels correlate with enteral tolerance and bowel length in infants with short bowel syndrome. J Pediatr. 2005;146(4):542547.

13. Bailly-Botuha C, Colomb V, Thioulouse E, Berthe MC, Garcette K, Dubern B, Goulet O, et al. Plasma citrulline concentration reflects enterocyte mass in children with short bowel syndrome. Pediatr Res. 2009;65(5):559-563.

14. Crenn P, Coudray-Lucas C, Thuillier F, Cynober L, Mess- ing B. Postabsorptive plasma citrulline concentration is a marker of absorptive enterocyte mass and intestinal failure in humans. Gastroenterology. 2000;119(6):1496-1505.

15. Bujold K, Hauer-Jensen M, Donini O, Rumage A, Hartman D, Hendrickson HP, Stamatopoulos J, et al. Citrulline as a biomarker for gastrointestinal-acute radiation syndrome: species differences and experimental condition effects. Radiat Res. 2016;186(1):71-78.

16. Ioannou HP, Fotoulaki M, Pavlitou A, Efstratiou I, Augoustides-Savvopoulou P. Plasma citrulline levels in paediatric patients with celiac disease and the effect of a gluten-free diet. Eur J Gastroenterol Hepatol. 2011;23(3):245-249.

17. Papadia C, Kelly P, Caini S, Corazza GR, Shawa T, Franze A, Forbes A, et al. Plasma citrulline as a quantitative biomarker of HIV-associated villous atrophy in a tropical enteropathy population. Clin Nutr. 2010;29(6):795-800.

18. Fjermestad H, Hvistendahl M, Jeppesen PB. Fasting and postprandial plasma citrulline and the correlation to intestinal function evaluated by 72-hour metabolic balance studies in short bowel jejunostomy patients with intestinal failure. JPEN J Parenter Enteral Nutr. 2018;42(2):418426.

19. Curis E, Nicolis I, Moinard C, Osowska S, Zerrouk N, Benazeth S, Cynober L. Almost all about citrulline in mammals. Amino Acids. 2005;29(3):177-205.

20. Morris JG, Rogers QR. Ammonia intoxication in the near-adult cat as a result of a dietary deficiency of arginine. Science. 1978;199(4327):431-432.

21. Gate JJ, Parker DS, Lobley GE. The metabolic fate of the amido-N group of glutamine in the tissues of the gastrointestinal tract in $24 \mathrm{~h}$-fasted sheep. Br J Nutr. 1999;81(4):297-306.

22. Curis E, Crenn P, Cynober L. Citrulline and the gut. Curr Opin Clin Nutr Metab Care. 2007;10(5):620-626.

23. Kohsaka A, Laposky AD, Ramsey KM, Estrada C, Joshu C, Kobayashi Y, Turek FW, et al. High-fat diet disrupts behavioral and molecular circadian rhythms in mice. Cell Metab. 2007;6(5):414-421.

24. Fatima J, Iqbal CW, Houghton SG, Kasparek MS, Duenes JA, Zheng Y, Sarr MG. Hexose transporter expression and function in mouse small intestine: role of diurnal rhythm. J Gastrointest Surg. 2009;13(4):634-641.

25. Houghton SG, Iqbal CW, Duenes JA, Fatima J, Kasparek MS, Sarr MG. Coordinated, diurnal hexose transporter expression in rat small bowel: implications for small bowel resection. Surgery. 2008;143(1):79-93.

26. Antokhin AI, Zharkova NA, Zakharchenko AV, Romanov YA. Rhythms of cell division of different periodicity in small intestinal cryptic epithelium and their contribution to circadian rhythm formation. Bull Exp Biol Med. 2012;152(4):486-488.

27. Suzuki H, Shibata S, Okutani T, Suzuki M, Nakayama M, Nishimura T, Doi K. Diurnal changes in intraepithelial lymphocytes (IELs) in the small intestine of mice. Exp Anim. 1999;48(2):115-118.

28. Zarrinpar A, Chaix A, Yooseph S, Panda S. Diet and feeding pattern affect the diurnal dynamics of the gut microbiome. Cell Metab. 2014;20(6):1006-1017. 